\title{
REFORMA TRABALHISTA: A PREVALÊNCIA DO NEGOCIADO SOBRE O LEGISLADO
}

\author{
Lorrayne da Silva Santos, Mari Ângela Pelegrini
}

Universidade do Oeste Paulista - UNOESTE, curso de Direito, Presidente Prudente, SP. E-mail: ayne_santos@hotmail.com

\section{RESUMO}

O presente trabalho tem como objetivo analisar a prevalência da negociação coletiva, via Acordo Coletivo de Trabalho ou Convenção Coletiva de Trabalho, sobre a legislação trabalhista à luz do Projeto de Lei $n^{\circ} 6.787$ de 2016, transformado na recente Lei Ordinária $n^{\circ} 13.467 / 2017$. Após verificar a natureza jurídica, conceitos básicos, suas características essenciais decorrentes da reforma trabalhista, foram apresentados os principais tópicos que poderão ser negociados e materializados nos instrumentos normativos, que farão lei entre as partes envolvidas. Destacamse: o fracionamento de férias; jornada de trabalho e remuneração por produtividade. Sugere, ao final, possíveis medidas que contribuirão para a eficiência e aplicabilidade do novo modelo, construído, pelo menos em tese, com maior liberdade, pelos próprios interessados.

Palavras-chave: Reforma. Trabalhista. Negociação. Coletiva. Legislado.

\section{LABOR REFORM: THE PREVALENCE OF THE NEGOTIATION ON LEGISLATION}

\begin{abstract}
The present study aims to analyze the prevalence of collective bargaining, through the Collective Bargaining Agreement or Collective Labor Convention, on labor legislation in the light of Bill No. 6,787 of 2016, transformed into the recent Ordinary Law 13,467 / 2017 . After verifying the legal nature, basic concepts and their essential characteristics resulting from the labor reform, the main topics that could be negotiated and materialized in the normative instruments were presented, which will make law between the parties involved. These include: vacation fractionation; Working hours and productivity pay. It suggests, at the end, possible measures that will contribute to the efficiency and applicability of the new model, built, at least in theory, with greater freedom, by the stakeholders themselves.
\end{abstract}

Keywords: Reform. Labor. Negotiation. Collective. Legislated.

\section{INTRODUÇÃO}

A reforma trabalhista é um dos temas que mais tem preocupado os juristas da atualidade, principalmente devido aos impactos que a flexibilização das leis trabalhistas, trará ao mundo do trabalho.

Sancionada pelo Presidente da República no dia 13 de julho de 2017, sob o número 13.467/2017, a lei citada altera substancialmente o Decreto- lei $n^{\circ} 5.452$ de 01 de Maio de 1943 e a lei $n^{\circ} 6.019$ de janeiro de 1974, mais conhecido pela sigla CLT, (Consolidação das Leis do Trabalho) e a antiga Lei do Trabalho Temporário, respectivamente, abrindo margem à construção de opiniões e discussões relevantes e muito divergentes a partir de diferentes pontos de vista.

Algumas das principais inovações da lei citada é a possibilidade de permanência de gestantes em locais considerados insalubres; aplicação de multa à empresas por funcionários nãoregistrados; extinção da obrigatoriedade de pagamentos de impostos sindicais e concessão aos acordos e convenções coletivas de trabalho força de lei, ou seja, quando as determinações 
contratuais colidirem com as normas legais, será considerado o que estiver acordado entre os contratantes.

Ocorre que, desde a década de 40 até meados de 2017, antes da promulgação da nova lei (que tem o período de vacância de 120 dias e previsão de entrada em vigor na primeira quinzena de novembro de 2017) as leis trabalhistas emanadas do Congresso Nacional, materializavam uma legislação trabalhista rígida no que diz respeito à observação de direitos e obrigações impostos e adquiridos, desde que mais benéficas ao trabalhador, por conta de princípios que protegiam os trabalhadores.

Os acordos e convenções coletivas passarão a prevalecer sobre a lei trabalhista. Prevalecendo para solução de conflitos entre as partes, ainda que negocie, como agora permitido, condições menos benéficas e mais prejudiciais aos trabalhadores. Mesmo que haja eventual arrependimento de uma das partes, por exemplo, uma vez estabelecidas novas regras e condições, o que resultar da negociação e materializado nos procedimentos formais para a homologação do conteúdo normativo, nos moldes do art.611-A da nova lei, incorporado à CLT, deve ser respeitado e, pelo menos a princípio, restará somente uma alternativa: aguardar o vencimento do contrato coletivo, cujas consequências daí advindas, é o objetivo deste estudo.

\section{METODOLOGIA}

O trabalho foi desenvolvido através de levantamento bibliográfico, principalmente em revistas especializadas, livros e artigos eletrônicos e bibliotecas digitais, tendo em vista a escassez de material sobre o tema e a recente edição da lei, no momento da elaboração da pesquisa. Empregando o método hipotético-dedutivo, a partir de análise qualitativa da legislação estudada, o confronto de dados embasou a conclusão nada otimista.

\section{DA REFORMA TRABALHISTA}

Após uma apressada tramitação no Congresso Nacional o Projeto de lei. $n^{\circ} 6.787$ de 2016, transformado na recente Lei Ordinária $n^{\circ} 13.467 / 2017$, foi sancionada pelo atual presidente da República, Michel Temer, com baixos índices de popularidade, diga-se de passagem, em meio ao maior escândalo de corrupção do país, na chamada Operação Lava-Jato, que, por sua vez, também envolveu vários parlamentares e políticos em nível nacional, retirando, alardeiam muitos, a legitimidade para a votação de lei de tamanha magnitude.

O texto finalizado na respectiva lei citada, altera disposições na Consolidação das Leis Trabalhistas e regulamenta novos parâmetros de contratação entre empregado e empregador. Apresentando uma nova possibilidade e alcance em relação a norma atualmente vigente, dentre tantas outras alterações, concedeu aos entes sindicais e para uma categoria de trabalhadores, com melhor poder aquisitivo, uma ampla margem de negociação, numa autonomia contratual perceptível, que foi, sem sombra de dúvida, o maior impacto da reforma.

\section{FLEXIBILIZAÇÃO}

O número de adeptos da chamada flexibilização cresce, aceleradamente, no Brasil. Oportuno, pois, antes se adentrar nos detalhes mais significativos da legislação, no que interessa a esse estudo, entender qual o significado do que seria exatamente a flexibilização das normas do direito do trabalho. No que diz respeito ao conceito mais técnico, seria, em uma concepção simplista e singela, a prevalência do negociado sobre o legislado, objeto central desta pesquisa e que inspirou o título deste artigo.

Nessa toada, Rodrigues, Aluisio et al. (1997, p.81) em crítica reducionista, em poucas palavras, sinaliza pela expressão "para alguns" e "para outros", a depender de que lado está o 
operador do direito, a favor da aceitação do instituto, ou não, destacando este fenômeno da seguinte forma:

Para alguns, a adequada diminuição do rigor excessivo de algumas leis trabalhistas que impedem maior eficiência do setor produtivo e do desenvolvimento econômico. Porém, flexibilizar, para outros não vai além de mero expediente que esconde sorrateiramente, o propósito de diminuir, simplesmente, direitos dos trabalhadores.

E se é para "diminuir" o rigor excessivo da lei e se é possível negociar inclusive para prejudicar o trabalhador, é notório que os acordos e convenções coletivas de trabalho materializaram uma forma de flexibilização das normas.

O Brasil atravessa a fase intervencionista, partindo para uma visão abstencionista, não no sentido de deixar de legislar sobre determinados assuntos, mas de oferecer autonomia aos contratantes para dispor em regras negociadas, via acordos e convenções coletivas de trabalho, quando não diretamente entre patrão e empregado (que no caso da reforma trabalhista entendeu ser possível para com aqueles trabalhadores que ganhem cerca de onze mil e poucos reais ou duas vezes o teto máximo de benefícios do INSS). A ideia é, portando, não interferir em suas relações, quando os direitos e obrigações não forem defesos em lei.

Faz tempo que os ventos da flexibilização sopram no Brasil. Exemplo de que a flexibilização das normas trabalhistas já era aceita há um bom tempo em nosso país, veio do legislador constituinte, basta relembrar o disposto na Constituição Federal (BRASIL, 1988):

Art. $7^{\circ}$ são direitos dos trabalhadores urbanos e rurais, além de outros que visem a melhoria de sua condição social:

[...] VI- Irredutibilidade salarial, salvo disposto em convenção ou acordo coletivo;

[...] XIII- Duração do trabalho normal não superior a oito horas diárias e quarenta horas semanais, facultada a compensação de horários e a redução da jornada, mediante acordo ou convenção coletiva de trabalho; (grifos nossos)

Todavia, houve resistência sindical e as negociações para redução salarial, por exemplo, foram raras e tímidas. Isso no passado, tempos em que os sindicatos tinham uma boa arrecadação; maior autonomia financeira e ideológica. Atualmente, sem a reforma sindical e a quebra aparente do monopólio da arrecadação (faculdade de oposição aos descontos e fim do imposto sindical) surgem correntes favoráveis à flexibilização das normas apenas do lado empresarial. Mas, claro, a corrente protecionista ao hipossuficiente, está dissonante e em desacorde com essa nova sistemática.

Nessa lógica contrária, há quase uma década, já salientava Andrade e Meller (2009, p.91):

É muito simples pregar 'Livre Negociação' num ambiente como esse marcado pelo desemprego, ou subemprego, a miséria, baixíssimos salários, concentração de rendas, índices alarmantes de lucratividade. É muito simples porque um dos atores - enfraquecido, preocupado em preservar os empregos existentes e ameaçado pela instabilidade e pela imensa legião de desempregados que batem às portas das fábricas - não tem qualquer possibilidade de sucesso, no sentido de implementar melhorias nas condições de vida e de trabalho dos seus representados. 
A flexibilização das normas trabalhistas, embora possível em hipóteses específicas, desde 1988, portanto, já é instituto antigo no Brasil, e o posicionamento de doutrinadores e estudantes do direito do trabalho foi construído com fundamentações muito convincentes, na linha do velho ditado: "quem pode o mais, pode o menos". Se já era possível reduzir até salários? Por que não o resto?

\section{ACORDOS COLETIVOS DE TRABALHO}

As disposições da recente Lei $13.467 / 2017$ assegura que a Consolidação das Leis Trabalhistas passa a vigorar de acordo com várias alterações sendo a que interessa a esse trabalho, aquele relativo a flexibilização, cujo conceito já foi analisado no tópico anterior, passa de hipóteses específicas, para uma amplitude que preocupou toda a classe operária, dentre as quais, destaca-se algumas, a título exemplificativo:

Art. 611-A. A convenção ou o acordo coletivo de trabalho tem força de lei quando dispuser sobre:

I - parcelamento de período de férias anuais em até três vezes, com pagamento proporcional às parcelas, de maneira que uma das frações necessariamente corresponda a, no mínimo, duas semanas ininterruptas de trabalho;

II - pacto quanto à de cumprimento da jornada de trabalho, limitada a duzentas e vinte horas mensais;

[...] XII - remuneração por produtividade, incluídas as gorjetas percebidas pelo empregado; [...]

As convenções coletivas são pactuadas entre entidades sindicais (patronais e de empregados) e os acordos coletivos entre sindicato de empregados (categoria profissional) e uma ou mais empresas específicas em negociação direta, sem a entidade sindical da categoria econômica.

Convenções coletivas de trabalho, segundo o raciocínio de Nascimento e Nascimento (2014, p.449) "é a norma jurídica resultantes das negociações entre trabalhadores e os empregadores, para autocomposição dos seus conflitos coletivos."

Diferentemente das Convenções, o acordo coletivo de trabalho no ponto de vista de Martins (2013, p.1202) é "O negócio jurídico entre o sindicato da categoria profissional e uma ou mais empresas pertencentes à categoria econômica sobre condições de trabalho."

O poder dado aos entes sindicais, talvez não seja benéfico ao empregado, mormente num país ainda sem ampla liberdade sindical e sem uma cultura de negociação eficaz. Mas, dizem os adeptos da flexibilização, que é preciso começar. Neste meio tempo, os trabalhadores que passam pela maior crise econômica já vivida em décadas, provavelmente serão cobaias e sofrerão os efeitos desta inovação.

Analisando a situação econômica do País, avassaladora do ponto de vista da crise, sem precedentes, a prevalência do acordado sobre a norma geral celetista ou constitucional, emanada do poder legislativo ou do constituinte originário, respectivamente, poderá ser utilizada como uma forma de intimidação aos empregados frente ao desemprego.

Vislumbra-se que haverá enfraquecimento das entidades sindicais e ou, no momento da contratação, de modo que a empresa apresentará suas condições e as cláusulas ditas normativas, sendo elas benéficas, ou não, ao empregado, deixando-os à mercê da sorte na relação de trabalho.

\section{PARCELAMENTO DE FÉRIAS}


Uma das hipóteses de discussão/negociação em acordos ou convenções coletivas é o fracionamento das férias anuais, em até três vezes, sendo que uma dessas não poderá ser inferior a duas semanas de trabalho ininterrupto.

As férias, é sabido, funcionam como um espécie de prêmio ao trabalhador, uma medida que favorece recuperação de energias físicas perdidas decorrentes do trabalho desenvolvido. (DELGADO, 2016)

Não restarão outras opções aos trabalhadores representados pelas entidades sindicais que participarem e aceitarem tal condição, senão o cumprimento integral do que fora convencionado. Ante essa perspectiva, o eventual arrependimento de uma das partes de nada valerá até a resolução do contrato e ou nova negociação que elimine a cláusula que for rejeitada.

\section{JORNADA DE TRABALHO}

Outro ponto destacado nesta pesquisa é a alteração da jornada de trabalho mediante acordo coletivo, com limite máximo de duzentas e vinte horas mensais.

Distinções relevantes são apresentadas entre duração e jornada de trabalho. Nesse sentido observamos as lições de Delgado, Maurício Godinho (2016, p.957)

Duração do trabalho é a noção mais ampla. Abrange o lapso temporal de labor ou disponibilidade do empregado perante seu empregador em virtude de contrato considerando-se distintos parâmetros de mensuração: dia, semana, e até mesmo ano. Jornada é expressão com sentido mais restrito, compreendendo o tempo diário em que o empregado tem de se colocar em disponibilidade perante seu empregador, em decorrência do contrato.

A limitação das duzentas e vinte horas mensais trouxe aparente benefícios ao empregado, uma vez que a negociação coletiva não poderá regulamentar jornadas excedentes. Porém, a jornada diária, na prática, poderá sofrer abusos.

\section{REMUNERAÇÃO POR PRODUTIVIDADE}

A Constituição Federal (BRASIL, 1988), assegura direitos básicos dos trabalhadores e garantias fundamentais, dentre eles a igualdade entre indivíduos. Porém, o princípio da isonomia poderá ser atingindo quando se trata de valoração aos resultados do trabalho de uma pessoa.

Casos onde é possível mensurar a produtividade por critérios objetivos do trabalho o disposto na nova lei poderá ser bem recepcionado. Porém, quando o trabalho é imensurável, por exemplo, trabalhos com desenvolvimento intelectual de difícil avaliação, uma negociação neste sentido não poderá contribuir e sim prejudicar as disparidades já existentes.

\section{CONCLUSÃO}

A pesquisa, nos exemplos declinados demonstrou que a reforma trabalhista, alterará diversos pontos já pacificados na Consolidação das Leis do Trabalho, favoráveis aos trabalhadores e, depois de longos anos de conquistas e pacificação da jurisprudência a flexibilização, era limitada e agora, não obstante a manutenção de supostas limitações, ampliou significativamente o campo de atuação das entidades sindicais, em momento em que estão fragilizadas, num cenário de crise econômica e desemprego, sem precedentes. Uma legislação que foi editada num momento de crise política com pouca credibilidade quanto aos benefícios por parte da comunidade operária, restando evidente que as convenções coletivas e acordos coletivo de trabalho, sem entidades sindicais fortalecidas, passarão a ser vistas sob olhares de diferentes juristas e caberá aos 
aplicadores da lei, a tarefa árdua de tentar conciliar o desejo da classe empresarial, mentora da flexibilização, com os princípios que protegem os trabalhadores e inspiram o direito do trabalho.

\section{REFERÊNCIAS BIBLIOGRÁFICAS}

ANDRADE; MELLER. $2009 . \quad$ Disponível em: <http://www.r2learning.com.br/_site/artigos/curso_oab_

concurso_artigo_798_A_flexibilizacao_das_normas_trabalhistas>. Acesso em:7 jul. 2017

BRASIL, Consolidação das Leis do Trabalho. Decreto-lei, $\mathrm{n}^{\circ}$ 5.452, de 1 de maio de 1943. Das normas gerais de tutela do trabalho. Disponível em: <http://www.planalto.gov.br/ccivil_03/decreto-lei/Del5452.htm>. Acesso em: 7 ago. 2017

BRASIL. Constituição da República Federativa do Brasil de 05 de outubro de 1988.. Diário Oficial da União, Brasília, 05 out. 1988 Disponível em: <http://www.planalto.gov.br/ccivil_03/constituicao/constituicaocompilado.htm >. Acesso em 06 jul. 2017

BRASIL. Decreto lei n. ${ }^{\circ} 13.467$ de 13 de julho de 2017. Altera a Consolidação das leis do trabalho, a fim de adequar a legislação às novas relações de trabalho. Diário Oficial da União, Brasília, 13 jun. 2017. Disponível em: <http://www.normaslegais.com.br/legislacao/Lei-13467-2017.htm>. Acesso em: 05 jul. 2017

CREPALDI, Joaquim Donizeti. O princípio de proteção e a flexibilização das normas de direito do trabalho. São Paulo: Ltr, 2003.

DELGADO, Mauricio Godinho. Curso de Direito do Trabalho. 15. ed. São Paulo: Ltr, 2016

MARTINS, Sergio Pinto. Direito do trabalho. 32. ed. São Paulo: Saraiva,2016

NASCIMENTO, A. M. ; NASCIMENTO,S. M. Curso de direito do Trabalho: História e teoria geral do direito do trabalho. 29. ed. São Paulo: Saraiva, 2014

RODRIGUES, A. et al. Direito Constitucional do trabalho. São Paulo: Ltr,1997 